\title{
Animal bites and rabies exposure in Australian travellers
}

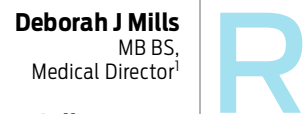

abies poses a threat to over 3.3 billion people worldwide, and causes an estimated Colleen L Lau MB BS, MPH\&TM FRACGP

PhD Candidate and Medical Co-Director ${ }^{2,3}$

Philip Weinstein MAppEpi, PhD, FAFPHM Adjunct Professor and Dean of Graduate Studies ${ }^{2,4}$

1 Dr Deb - The Trave Doctor, Brisbane, QLD.

2 School of Population Health, University of Queensland Brisbane, QLD.

3 Travel Medicine Centre Perth, Perth, WA.

4 Graduate Research Centre, University of

South Australia,

Adelaide, SA.

colleen.lau@ uqconnect.edu.au

MJA 2011; 195: 673-675 doi: 10.5694/mjal0.11413

55000 deaths each year. ${ }^{1}$ The disease is endemic in Asia, Africa, Europe and the Americas, and is maintained by a wide range of animals. The vast majority of deaths occur in Asia and Africa and, annually, more than 15 million people receive postexposure prophylaxis (PEP) for rabies. ${ }^{1}$ Australia is free of rabies, but Australian bat lyssavirus causes a rabies-like illness. ${ }^{2}$

Australians make 6.8 million shortterm international departures each year, with over 3 million of these to Asia. ${ }^{3}$ Many travellers are therefore exposed to the risk of rabies. The emergence of rabies in Bali, Indonesia, since 2008 has resulted in over 100 human deaths, ${ }^{4}$ and returned travellers from Bali now account for a significant proportion of those seeking rabies PEP in Australia. ${ }^{5}$

Travellers can be protected from rabies by either vaccination before exposure, or PEP. The World Health Organization (WHO) recommendations for PEP include prompt wound cleaning, administration of rabies immunoglobulin (RIG) into or around the wound, followed by a course of rabies vaccines. ${ }^{1}$ Ideally, PEP should be commenced as soon as possible after any potential exposure to rabies. Although it is possible for travellers to seek PEP overseas, it can be difficult for them to obtain treatment promptly, and RIG is often unavailable. ${ }^{1}$ Vaccination against rabies before exposure eliminates the need for RIG, reduces the number of vaccine doses after a potential exposure, and reduces the urgency of starting PEP.

The Australian National Health and Medical Research Council (NHMRC) immunisation guidelines recommend pre-exposure rabies vaccination for: ${ }^{2}$

- "Expatriates and travellers who will be spending prolonged periods (ie, more than a month) in rabies-endemic areas. (NB. This time interval, of more than a month, is arbitrary, and rabies

\section{Abstract}

Objectives: To examine the circumstances of animal exposure in a case series of Australian travellers who required rabies postexposure prophylaxis, and to assess the appropriateness of current guidelines for rabies pre-exposure vaccination.

Design, participants and setting: Prospective case series of 65 returned travellers who presented to four Australian travel medicine clinics between 1 April 2009 and 31 July 2010 for rabies post-exposure prophylaxis.

Main outcome measures: Demographic characteristics associated with risk of injury; countries where injuries occurred; circumstances of the injuries; and travellers' experiences of obtaining postexposure prophylaxis overseas.

Results: Animal bites and scratches occurred most commonly among travellers aged 20-29 years. Most injuries occurred in Bali, Indonesia (30 [46\%]) and Thailand (21 [32\%]), and the most common animals responsible for the injuries to the 65 travellers were monkeys (29 travellers [45\%]) and dogs (27 [42\%]). Thirty-nine of the travellers (60\%) initiated contact with the animal. Forty travellers (62\%) were able to commence rabies vaccination overseas, but only nine (14\%) were able to obtain rabies immunoglobulin overseas.

Conclusions: Most travellers had difficulty obtaining rabies postexposure prophylaxis overseas, resulting in significant delays in appropriate treatment. We recommend that current National Health and Medical Research Council guidelines for at-risk persons be broadened, and that the risk of rabies and the option of pre-exposure vaccination be discussed with all travellers to rabies-endemic areas.

has occurred in travellers following shorter periods of travel)", and

- "People working with mammals in rabies-endemic areas".

In this article, we pose the question: Are the current Australian guidelines for rabies pre-exposure vaccination appropriate, given the common circumstances in which travellers are exposed to animal bites? To examine this question, we report a case series of travellers who were bitten or scratched by animals in rabies-endemic areas and sought PEP on their return to Australia. We describe the circumstances of their exposure and their experience with obtaining PEP overseas, and we consider these findings in the context of the current NHMRC guidelines for rabies vaccination.

\section{Methods}

We collected data on travellers who were bitten or scratched by animals in rabies-endemic areas, and who presented to three travel medicine clinics in Queensland (Brisbane, Gold Coast, and Maroochydore) and one in Western Australia (Perth) between 1 April 2009 and 31 July 2010. All returned travellers who presented for PEP were included, and the treating doctor used a questionnaire to collect the data.

\section{Data collection}

The questionnaire used by doctors at each clinic sought routine information on:

- demographic characteristics of the injured traveller;

- the geographical location where the injury occurred;

- the nature of the injury;

- the type of activity the traveller was engaged in when injury occurred, and any initiation of animal contact; - pre-exposure rabies vaccination; and

- PEP obtained overseas and on return to Australia.

\section{Results}

The 65 returned travellers (45 from Queensland and 20 from Perth) who presented for PEP during the 16month study period included 36 males (55\%) and 29 females (45\%). The highest number of injuries was seen in travellers aged 20-29 years. Box 1 shows the age distribution of travellers in our study compared with 

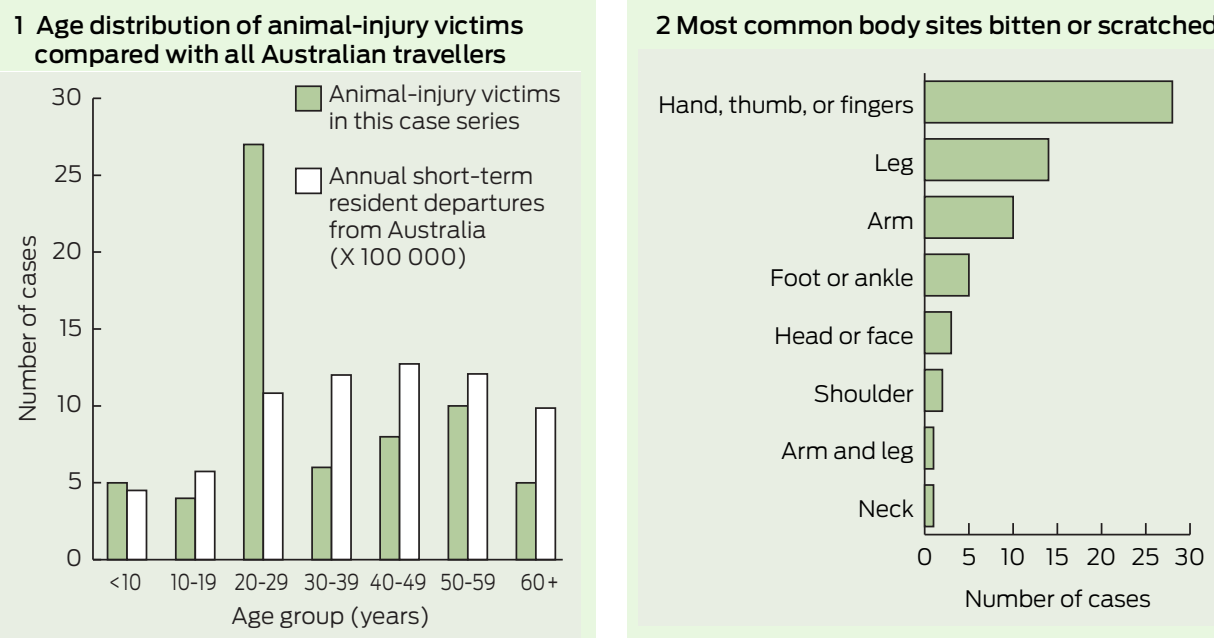

the age distribution of all Australian residents making short-term departures from Australia in 2010. ${ }^{6}$

\section{Circumstances of animal exposure}

Fifty-one travellers (78\%) reported bites, and 11 (17\%) reported scratches. The most common body parts injured were the hand (including thumb or fingers), followed by the leg and the arm (Box 2).

Box 3 shows that the most common destinations where travellers were injured were Bali, Indonesia (30 travellers [46\%]), and Thailand (21 [32\%]). Currently, $9.6 \%$ of Australian shortterm resident departures are made to Indonesia, and $6.4 \%$ to Thailand. ${ }^{3}$

Injuries in our series occurred with equal frequency in urban (23 travellers [35\%]) and rural (22 [34\%]) areas; 10 travellers $(15 \%)$ were injured at an animal park or zoo. Of the 30 travellers injured in Bali, 18 (60\%) were bitten or scratched by monkeys, and 13 travellers $(43 \%)$ were injured while feeding or interacting with the animals at a "monkey forest" or "monkey temple".

The animals most commonly responsible for injuries were monkeys (29 travellers [45\%]) and dogs (27 [42\%]), but other species included cats, an orangutan, and a tiger. Thirty-nine of the travellers (60\%) initiated contact with the animal. This included patting, touching, or picking up the animal (14 travellers); feeding the animal (10); taking photographs of or having photographs taken with the animal (5); and reaching for or waving at the animal, or shooing it away (5). Twenty-two travellers (34\%) were bitten without

* Rabies immunoglobulin and vaccines. initiating contact with animals, and none were working with animals.

Travellers were injured a mean of 15.3 days after their departure from Australia (range, 0-95 days), and 51 out of $58(88 \%)$ were injured within 30 days. The timing of exposure was unknown for the other seven travellers.

\section{Pre-exposure rabies vaccination and postexposure prophylaxis}

Only one traveller had received preexposure rabies vaccination. Forty travellers (62\%) commenced PEP while overseas, and only nine of these $(14 \%)$ were able to obtain RIG. Some travellers received RIG after they returned to Australia, and those who presented more than 7 days from their first rabies vaccine dose did not receive RIG (as recommended by the NHMRC). ${ }^{2}$ Overall, only 35 travellers (54\%) completed PEP as recommended by the $\mathrm{WHO}$ and received RIG and all doses of the vaccine; 29
3 Countries where injuries occurred, and the type of animal involved

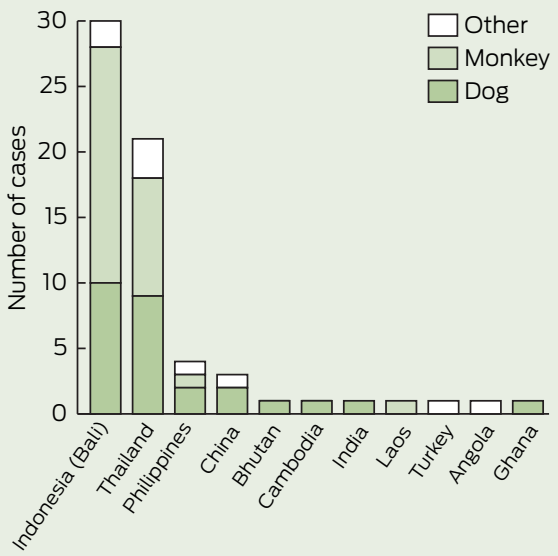

travellers $(45 \%)$ received vaccines only (Box 4).

The 36 travellers who received RIG were treated an average of 13.2 days after the injury (range, 0-134 days), and only four obtained RIG within 48 hours. Of the 61 travellers who received the vaccine, the average delay in starting the vaccination was 9.1 days, but 33 (54\%) received the first dose within 48 hours.

\section{Discussion}

In our case series, most injuries occurred less than 30 days after arriving in rabies-endemic areas, and none of the travellers were working with animals. Many travellers also did not fall into other categories that are traditionally considered "high-risk" (eg, prolonged travel, travelling to rural areas, participating in outdoor adventures, working with animals, or planned activities involving animals).

\section{Postexposure prophylaxis in 65 travellers who were injured by animals while overseas in rabies-endemic countries}

Details of postexposure prophylaxis

Started postexposure prophylaxis overseas after bite

Yes

No

Received rabies immunoglobulin overseas

Yes

No

Not required

Unknown

Received all doses of postexposure prophylaxis*

Yes

No

Unknown
No. (\%) of travellers

$40(62 \%)$

$25(38 \%)$

$9(14 \%)$

$54(83 \%)$

$1(2 \%)$

$1(2 \%)$

$35(54 \%)$

$29(45 \%)$

$1(2 \%)$ 
The most common sites for animal bites were hands and fingers, which are high-risk areas for rabies transmission because of rich nerve supplies.

Most travellers were injured while engaging in common tourist activities. More than a third did not initiate contact with animals, which indicates that advising travellers to avoid animals does not guarantee that they will not be bitten.

Our study highlights Indonesia (Bali) and Thailand as particularly high-risk destinations. Considering the recent emergence of rabies in Bali since 2008, ${ }^{7}$ and the disproportionate number of travellers who were injured while feeding or interacting with monkeys at a monkey temple or monkey forest, we recommend that all travellers to Bali should be warned against these highrisk activities. Travellers aged between 20 and 29 years are at particular risk, and special consideration should be given to this age group when recommending rabies pre-exposure vaccination.

There are potential sources of bias in the study, because it only included travellers who presented to travel clinics on return to Australia, and only clinics in Queensland and Western Australia. Potential exposures are also likely to be underreported, and some travellers might not seek PEP after injuries. Travellers who present to travel clinics are potentially better informed about the risk of rabies, and more motivated to seek PEP.

Our findings confirm the difficulties of obtaining adequate PEP and RIG in developing countries. ${ }^{5,8-10}$ As a result, there were delays in starting PEP, and only half of our travellers were able to comply with WHO recommendations.
With the current worldwide shortage of human $\mathrm{RIG}^{1}{ }^{1}$ difficulties of access are likely to continue. Delays in starting or failure to complete timely PEP may result in vaccine failure and the risk of fatal rabies infection. ${ }^{11}$ Pre-exposure vaccination against rabies will also reduce the cost of PEP to the health care system, but additional evidence would be required to inform a formal costbenefit analysis.

Rabies vaccination is safe and effective, and provides long-term protection. ${ }^{1}$ Pre-exposure vaccination using the intradermal route has been proven to be safe and effective for immunocompetent people when performed at a travel medicine clinic with adequately trained nurses, and can be completed at a third of the cost of intramuscular injections. ${ }^{1,12}$ However, postvaccination serological testing is recommended 2-3 weeks after an intradermal course to confirm immunity, ${ }^{2}$ and some travellers will not have sufficient time to complete this before departure.

Based on our findings, we recommend that all travellers to rabiesendemic areas should be counselled about the risk of animal bites, warned about high-risk behaviours, and given the option of pre-exposure vaccination. They should be advised about PEP in case of exposure, the difficulties of obtaining PEP in some parts of the world, and should be allowed to make an informed decision about whether pre-exposure vaccination is appropriate for their circumstances.

Acknowledgements: We thank the staff at the Travel Medicine Alliance clinics in Queensland and Western Australia for collecting the data for our study.

Competing interests: No relevant disclosures.
Received 2 Dec 2010, accepted 30 Jun 2011.

1 World Health Organization. Rabies vaccines: WHO position paper. Wkly Epidemiol Rec 2010; 85: 309 320. http://www.who.int/wer/2010/wer8532.pdf (accessed Nov 2011).

2 National Health and Medical Research Council. Australian bat lyssavirus infection and rabies. Section 3.1. In: The Australian immunisation handbook [internet]. 9th ed. Canberra: Australian Government Department of Health and Ageing, 2009. http://www.immunise.health. gov.au/ internet/immunise/publishing.nsf/Content/ Handbook-lyssavirus (accessed Nov 2011).

3 Australian Bureau of Statistics. Table 9: Short-term movement, resident departures - selected destinations: original. In: Overseas arrivals and departures, Australia, August 2010. Canberra: ABS, 2010. (ABSCat. No. 3401.0.) http://www. abs.gov.au/AUSSTATS/abs@.nsf/DetailsPage/ 3401.0Aug\%202010?OpenDocument (accessed Nov 2011).

4 Pro-MED-mail. Rabies, human - Indonesia (18): Bali. 2010; 25 November. (Archive No. 20101125.4254.) http://www.promedmail.org (accessed 20 Nov 2011).

5 Gautret P, Lim PL, Shaw M, Leder K. Rabies postexposure prophylaxis in travellers returning from Bali, Indonesia, November 2008 to March 2010. Clin Microbiol Infect 2011; 17: 445-447.

6 Australian Bureau of Statistics. Overseas arrivals and departures, Australia, Dec 2010. Canberra: ABS, 2010. (ABSCat. No. 3401.0.) http://www. abs.gov.au/AUSSTATS/abs@.nst/allprimarymain features/5738001A6AID48F5CA25784900 12A3D7?opendocument (accessed Nov 2011).

7 Pro-MED-mail. Rabies, canine, human - Indonesia (21): Bali. 2009; 29 December.

(Archive No. 20091229.4373.) http://www. promedmail.org (accessed Nov 2011).

8 Wilde H, Briggs DJ, Meslin FX, et al. Rabies update for travel medicine advisors. Clin Infect Dis 2003; 37: 96-100.

9 Shaw MT, O'Brien B, Leggat PA. Rabies postexposure management of travelers presenting to travel health clinics in Auckland and Hamilton, New Zealand. J Travel Med 2009; 16: 13-17.

10 Gautret P, Shaw M, Gazin P, et al. Rabies postexposure prophylaxis in returned injured travelers from France, Australia, and New Zealand: a retrospective study. J Travel Med 2008; 15: 25-30.

11 Wilde H, Sirikawin S, Sabcharoen A, et al. Failure of postexposure treatment of rabies in children. Clin Infect Dis 1996; 22: 228-232.

12 LauC, Sisson J. The effectiveness of intradermal pre-exposure rabies vaccination in an Australian travel medicine clinic. J Travel Med 2002; 9: 285-288. 